Check for updates

Cite this: Mater. Adv., 2020 1,2271

Received 24th July 2020, Accepted 20th September 2020

DOI: 10.1039/d0ma00538j

rsc.li/materials-advances

\title{
Robust, remeltable and remarkably simple to prepare biomass-sulfur composites $\dagger$
}

\author{
Moira K. Lauer, ${ }^{a}$ Menisha S. Karunarathna, ${ }^{a}$ Andrew G. Tennyson iD ${ }^{\text {ab }}$ and \\ Rhett C. Smith iD *a
}

\begin{abstract}
Lignocellulosic biomass holds a tremendous opportunity for transformation into carbon-negative materials, yet the expense of separating biomass into its cellulose and lignin components remains a primary economic barrier to biomass utilization. Herein is reported a simple procedure to convert several biomass-derived materials into robust, recyclable composites through their reaction with elemental sulfur by inverse vulcanization, a process in which olefins are crosslinked by sulfur chains. In an effort to understand the chemistry and the parameters leading to the strength of these composites, sulfur was reacted with four biomass-derivative comonomers: (1) unmodified peanut shell powder, (2) allyl peanut shells, (3) 'mock' allyl peanut shells (a mixture containing independently-prepared allyl cellulose and allyl lignin), or (4) peanut shells that have been defatted by extraction of peanut oil. The reactions of these materials with sulfur produce the biomass-sulfur composites $\mathbf{P S}_{\boldsymbol{x}}, \mathbf{A P S}_{\boldsymbol{x}}, \mathbf{m A P S}_{\boldsymbol{x}}$ and dfPS $_{\boldsymbol{x}}$, respectively, where $x=w t \%$ sulfur in the monomer feed. The influence of biomass: sulfur ratio was assessed for $\mathbf{P S}_{\boldsymbol{x}}$ and $\mathbf{A P S}_{\boldsymbol{x}}$. Thermal/mechanical properties of composites were evaluated for comparison to commercial materials. Remarkably, unmodified peanut shell flour can simply be heated with elemental sulfur to produce composites having flexural/compressive strengths exceeding those of Portland cement, an effect traced to the presence of olefin-bearing peanut oil in the peanut shells. When allylated peanut shells are used in this process, a composite having twice the compressive strength of Portland cement is attained.
\end{abstract}

\section{Introduction}

Lignocellulosic biomass constitutes the most abundant and underutilized by-product of human industry, yet the economic conversion of biomass into fuels and feedstocks for chemical processes remains one of the great challenges in science. There is little doubt that harnessing biomass is the key to the future green economy needed to ensure the sustainability and resilience of civilization, and while great strides have been made in developing efficient processes for the conversion of cellulose to fuel ethanol, the need to separate lignin from cellulose prior to that conversion greatly detracts from the economy of the process. ${ }^{1-5}$ Even once separated, the lignin is a high-volume,

\footnotetext{
${ }^{a}$ Department of Chemistry, Clemson University, Clemson, South Carolina, 29634, USA.E-mail: rhett@clemson.edu

${ }^{b}$ Department of Materials Science and Engineering, Clemson University, Clemson, South Carolina, 29634, USA

$\dagger$ Dedicated to John D. Protasiewicz for his contributions to using main group elements in polymer science.

\# Electronic supplementary information (ESI) available: Proton NMR spectral data, FTIR spectra, TGA curves, analysis of char yield versus composition; DSC curves. See DOI: 10.1039/d0ma00538j
}

low-value commodity whose full potential has yet to be leveraged. ${ }^{6}$

As part of our ongoing effort to explore the viability of lignocellulosic biomass as a precursor to durable composites, we recently reported a process by which agricultural by-product peanut shells can be converted to a composite having mechanical properties that rival those of familiar structural materials like Portland cement. ${ }^{7}$ This process involved a low-temperature aqueous olefination of finely-ground peanut shell powder (particle size $\leq 300 \mu \mathrm{m}$, Fig. S1, ESI $\ddagger$ ) and subsequent polymerization by the $\sim 100 \%$ atom-economical inverse vulcanization upon reaction with elemental sulfur to yield $\mathbf{A P S}_{\mathbf{9 5}}$ (Scheme 1, $x=\mathrm{wt} \%$ sulfur in the monomer feed). Inverse vulcanization is a process in which olefins are crosslinked upon their reaction with thermally-generated sulfur radicals (Scheme 2) and has proven quite versatile to prepare high sulfur-content materials (HSMs) from both naturally-occurring and synthetic olefin crosslinkers. $^{8-11}$ Such high sulfur-content materials can be used in a variety of applications including thermal imaging, batteries, structural materials and water purification, driving the development of innovative synthetic and processing approaches. ${ }^{12-36}$ Significant advances have been made in lowering the reaction temperature and controlling curing of HSMs 

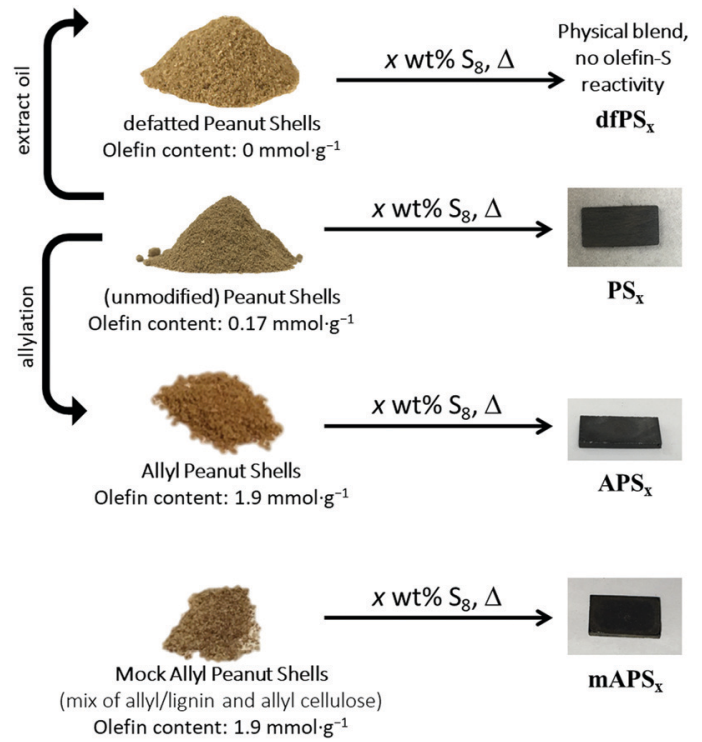

Scheme 1 Preparation of biomass-sulfur composites, where $x$ denotes wt\% sulfur in the monomer feed.

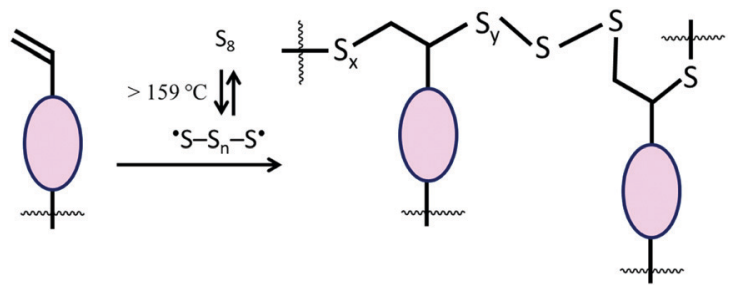

Scheme 2 Schematic for the general inverse vulcanization process.

through the use of prepolymers, ${ }^{23}$ ternary systems ${ }^{15}$ or catalysts. ${ }^{14,37}$ Pioneering insight into facile processing techniques relying on a clever $\mathrm{S}-\mathrm{S}$ metathesis process have made HSMs even more attractive as candidates for commercial applications by opening up the possibility for their use in additive manufacturing and compression moulding. ${ }^{38,39}$

Encouraged by advances in HSM processing and the high mechanical strength of $\mathbf{A P S}_{\mathbf{9 5}}$, we hypothesized that the properties of durable biomass-sulfur composites could be tuned by subtly changing the biomass : sulfur ratio or biomass composition in monomer feeds. We also hypothesized that unsaturated triglycerides that make up naturally occurring plant oils - present to varying extent in lignocellulosic waste streams - could contribute to crosslinking in biomass-sulfur composites derived from lessprocessed sources. The inverse vulcanization of triglycerides from a variety of plant oils has been reported ${ }^{16,19,20,37,40-43}$ and high mechanical strength can be achieved with relatively low ( $\leq 5 \mathrm{wt} \%)$ triglyceride content. ${ }^{44}$ The presence of plant oils could thus be an important factor in predicting how predominantly lignocellulosic biomass sources would perform as comonomers with sulfur. To test these hypotheses, a range of biomass-sulfur composites were prepared (Scheme 1). To prepare the HSMs, elemental sulfur was polymerized with one of several biomass-derived comonomers: (1) peanut shells (which contain some peanut oil) to give $\mathbf{P S}_{\boldsymbol{x}}$; (2) allylated peanut shells to give $\mathbf{A P S}_{\boldsymbol{x}}$, (3) 'mock' allylated peanut shells to give $\mathbf{m A P S}_{\boldsymbol{x}}$, and defatted peanut shells to give $\mathbf{d f P S}_{\boldsymbol{x}}$. For all the materials prepared, $x=\mathrm{wt} \% \mathrm{~S}$ in the monomer feed, and each biopolymer-sulfur composite had either 5 or $10 \mathrm{wt} \%$ of biomass crosslinker in the monomer feed.

The mock allylated peanut shell material was comprised of lignin and independently-synthesized allyl lignin and allyl cellulose mixed in such proportion as to accomplish the same lignin: cellulose ratio and to have the same concentration of olefins per unit mass as the authentic allylated peanut shells have. A comparison of properties for APS $_{\boldsymbol{x}}$ versus those for mAPS $_{\boldsymbol{x}}$ was conceived as a way to assess the extent to which properties are affected by the presence of lignin-cellulose crosslinks in $\mathbf{A P S}_{\boldsymbol{x}}$ but not in the cellulose-lignin physical blend used to prepare $\mathbf{m A P S}_{\boldsymbol{x}}$. The defatted peanut shells have had the peanut oil extracted prior to their reaction with sulfur to preclude the involvement of unsaturated triglycerides in the attempted crosslinking reaction. A comparison of the properties of $\mathbf{P S}_{\boldsymbol{x}}$ to $\mathbf{d f P S}_{\boldsymbol{x}}$ should thus inform on the extent to which triglyceride crosslinking contributes to material properties. The thermal and mechanical properties of the biomass-sulfur materials were characterized for comparison to familiar structural materials. In some cases, flexural and compressive strengths twice those of portland cement are accomplished in the biomass-sulfur composites.

\section{Results and discussion}

\section{Synthesis of biomass-sulfur composites}

We recently reported a method to allylate finely-ground peanut shells as a representative sample of lignocellulosic biomass (Fig. S1, ESI+). ${ }^{7}$ This simple aqueous allylation process gave allylated peanut shells containing $1.9 \mathrm{mmol}$ olefin per g material (determined by iodometric titration, the details of which can be found in the ESI $\$$ ). The allylated peanut shells were used directly as the organic monomer in inverse vulcanization with $95 \mathrm{wt} \%$ sulfur to give $\mathbf{A P S}_{95}$ (Scheme 1). An expanded set of biomass-sulfur composites was targeted for the current study in an effort to better understand the process and delineate the factors that influence mechanical properties. Compositions of the four biomass-derived monomers selected for this purpose are summarized in Scheme 1 and Table 1.

One goal of the current study was to assess the influence of biomass content on composite properties. $\mathbf{A P S}_{\mathbf{9 0}}$ was thus prepared with twice the biomass content in the monomer feed as compared to $\mathbf{A P S} \mathbf{9 5}_{\mathbf{9 5}}$. Both $\mathbf{A P S} \mathbf{9 0}_{\mathbf{9 0}}$ and $\mathbf{A P S} \mathbf{9 5}_{\mathbf{9 5}}$ are dark-coloured, readily-remeltable materials that are readily re-shaped by simply melting and pouring into moulds, where they are allowed to cure under ambient conditions (Scheme 1). Composites $\mathbf{P S}_{\boldsymbol{x}}$, made from sulfur and unmodified peanut shells were also prepared having 5 or $10 \mathrm{wt} \%$ of biomass for comparison.

Another goal of the current study was to assess the extent to which potential cellulose-lignin crosslinking present in allylated peanut shells contributes to the strength of the resulting 
Table 1 Composition and olefin content of biomass derivatives used as crosslinkers

\begin{tabular}{|c|c|c|c|c|}
\hline Biomass derivative $^{a}$ & $\begin{array}{l}\text { Cellulose: } \\
\text { lignin ratio }\end{array}$ & $\begin{array}{l}\text { Oil } \\
\text { content } \\
(w t \%)\end{array}$ & $\begin{array}{l}\text { Olefin } \\
\text { content } \\
\left(\mathrm{mmol} \mathrm{g}^{-1}\right)\end{array}$ & $\begin{array}{l}\text { Resultant } \\
\text { composite }\end{array}$ \\
\hline Allyl peanut shells & $3: 2$ & 0 & $1.9 \pm 0.04^{b}$ & $\mathbf{A P S}_{x}$ \\
\hline Unmodified peanut shells & $3: 2$ & $1^{c}$ & $\begin{array}{l}0.17 \pm \\
0.05^{b}\end{array}$ & $\mathbf{P S}_{x}$ \\
\hline Mock allyl peanut shells ${ }^{f}$ & $3: 2$ & 0 & $1.9^{d}$ & $\operatorname{mAPS}_{x}$ \\
\hline Defatted peanut shells ${ }^{g}$ & $3: 2$ & 0 & 0 & $\operatorname{dfPS}_{x}$ \\
\hline
\end{tabular}

${ }^{a}$ Each biomass derivative was filtered to pass a $300 \mu \mathrm{m}$ sieve prior to polymerization. ${ }^{b}$ Determined by iodometric titration. ${ }^{c}$ Determined by mass loss upon hexanes extraction. ${ }^{d}$ Determined by iodometric titration and ${ }^{31} \mathrm{P}$ NMR spectrometry of phosphidylated derivative. ${ }^{e}$ The subscript $x$ in the names indicates the wt\% of sulfur in the monomer feed. ${ }^{f}$ A mixture of lignin with independently-prepared allyl cellulose and allyl lignin. ${ }^{g}$ Peanut shells from which the peanut oil has been extracted with hexanes.

biomass-sulfur composites. Towards this end a 'mock' allylated peanut shell powder was prepared by mixing independentlyprepared samples of lignin, allyl lignin and allyl cellulose in such a ratio as to accomplish the same lignin : cellulose ratio and olefin content as in the allyl peanut shells that were prepared directly from the raw peanut shell powder. Composite $\mathbf{m A P S}_{95}$, prepared by the reaction of mock peanut shells and sulfur, led to a remeltable solids that was quite similar in appearance to $\mathbf{A P S}_{\boldsymbol{x}}$ (Scheme 1).

A third goal of the current study was to assess whether plant oils in biomass waste might contribute to material properties of the biomass-sulfur composites. Plant oils are comprised primarily of unsaturated triglycerides, which are known substrates for inverse vulcanization. ${ }^{16,17,20,40-42}$ Peanut shells generally contain about $1 \mathrm{wt} \%$ peanut oil. ${ }^{45}$ The peanut oil triglycerides are comprised of $18 \%$ saturated, $50 \%$ monounsaturated ( $48 \%$ oleate) and $31 \%$ polyunsaturated (30\% linoleate) fatty acid chains. ${ }^{46}$ Although the peanut oil content of peanut shells is only $1 \mathrm{wt} \%$, the storage modulus of elemental sulfur is known to increase by nearly an order of magnitude when it undergoes inverse vulcanization with just $1 \mathrm{wt} \%$ of free fatty acids linoleic acid $^{26}$ or oleic acid. ${ }^{30}$ Furthermore, each triglyceride molecule already links three fatty acid molecules, comprising up to six olefins in the case of a triglyceride having three linoleate chains, effectively increasing the crosslink density compared to that afforded by the free fatty acids. If crosslinking of sulfur by the peanut oil present in the peanut shells provides sufficient strength to the composite materials, then peanut shells would not need to be allylated to produce durable materials, which would clearly be a significant improvement in terms of the sustainability and affordability of the process. In a broader context, understanding how the presence of plant oils influences properties could be an important factor in identifying other privileged biomass sources for production of durable materials by the current route.

To first confirm the presence of unsaturated peanut oil triglycerides in the peanut shell product used for the current study, a sample of the ground peanut shell powder was extracted with hexanes, in which peanut oil is soluble but

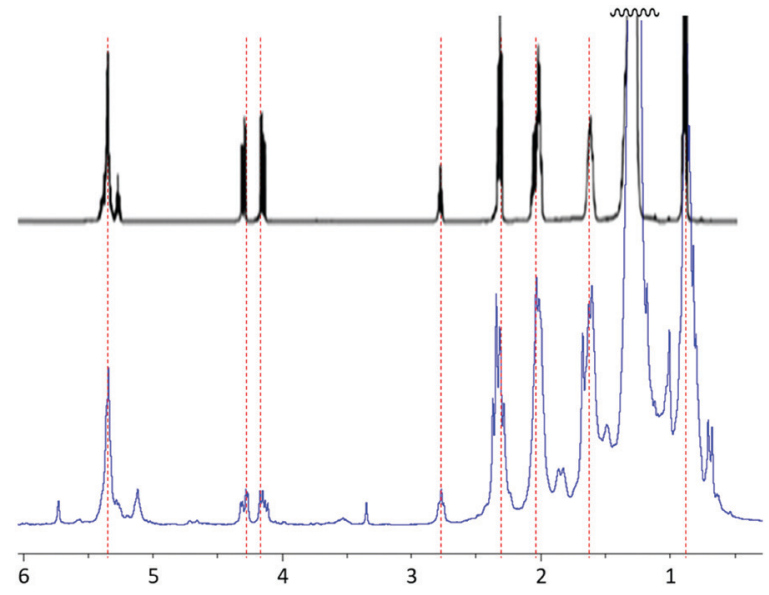

Fig. 1 Proton NMR spectra in $\mathrm{CDCl}_{3}$ for isolated peanut oil (upper spectrum) and hexanes-extractable material (lower spectrum) from peanut shells used to prepare $\mathbf{P S}_{\boldsymbol{x}}$. The spectrum for isolated peanut oil is reprinted from $\mathrm{E}$. G. Silveira Jr, et al., Potential of Virginia-type peanut (Arachis hypogaea L.) as feedstock for biodiesel production, Ind. Crops Prod., 89, 451, (C) 2016, with permission from Elsevier.

proteins, lignin, cellulose and hemicellulose are quite insoluble. The hexanes solvent was removed under reduced pressure, and the hexanes-soluble material was found to account for $1 \%$ of the peanut shell mass.

Analysis of the hexanes-extractable material by ${ }^{1} \mathrm{H}$ NMR spectrometry and comparison to a literature spectrum for peanut oil (Fig. 1) confirmed that the hexanes-soluble extract consists primarily of peanut oil, though there are also some other less intense resonances present that cannot be definitively assigned to peanut oil. Additional confirmation and quantification of unsaturation content in the peanut shells was obtained by iodometric titration of the peanut shell power, from which it was determined that the raw shells have an olefin content of $0.17 \mathrm{mmol} \mathrm{g}^{-1}$.

Having confirmed that the unmodified peanut shells contained the olefin moieties needed for crosslinking by sulfur, the shells were tested by their reaction with 90 or $95 \mathrm{wt} \%$ elemental sulfur to form composites $\mathbf{P S}_{\boldsymbol{x}}$ ( $x=$ wt $\%$ sulfur in monomer feed). When raw peanut shell powder is heated with elemental sulfur at $180{ }^{\circ} \mathrm{C}$, durable composites are in fact produced that are remeltable and similar in appearance to $\mathbf{A P S}_{\boldsymbol{x}}$ (Scheme 1).

If the presence of peanut oil is the critical feature that allows raw peanut shell powder to serve as a substrate for inverse vulcanization, then peanut shells from which peanut oil has been extracted should not produce a homogenous material, but rather a physical blend of peanut shell powder and sulfur. As a control experiment, defatted peanut shells (resulting from the hexanes extraction study described above) were thus heated with sulfur to yield composite materials dfPS $x_{x}$ comprising 90 or 95 wt\% sulfur (Scheme 1).

Scanning electron microscopy with element mapping by energy-dispersive X-ray analysis (SEM-EDX) confirmed that $\mathbf{d f P S}_{\mathbf{9 5}}$ and $\mathbf{d f P S}_{\mathbf{9 0}}$ are physical blends in which unreacted peanut shell particles are clearly visible (Fig. 2). These results are consistent with our previously reported findings that a physical blend of sulfur and either unmodified cellulose or unmodified lignin is 

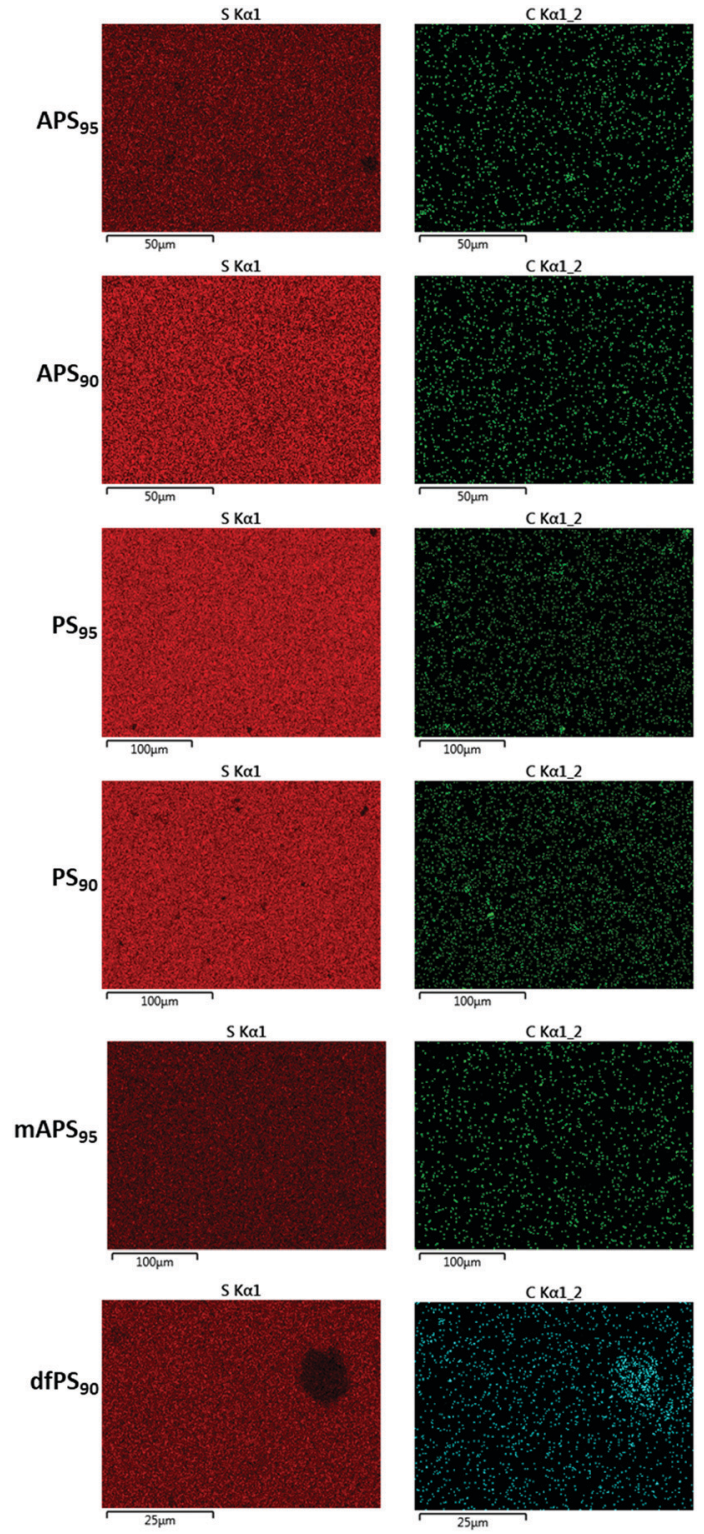

Fig. 2 Surface analysis of biomass-sulfur composites by EDX revealed the homogeneous distribution of sulfur (left) and carbon (right) for biomass-sulfur composites. Voids in the sulfur map where high carbon content is observed are identified as unreacted peanut shell particles in the physical blend $\mathbf{d f P S}_{\mathbf{9 0}}$.

likewise heterogeneous and phase-separates. ${ }^{27,32}$ In contrast to what was observed for $\mathbf{d f P S}_{\boldsymbol{x}}$, the SEM-EDX analyses shown in Fig. 2 provides evidence that olefin-containing $\mathbf{A P S}_{\boldsymbol{x}}, \mathbf{P S}_{\boldsymbol{x}}$ and mAPS $_{\boldsymbol{x}}$ all form microscopically homogeneous materials. All of these materials show a uniform distribution of sulfur, carbon and oxygen (carbon and sulfur maps are provided in Fig. 2, while oxygen elemental maps are included in the ESI $\neq$ file, Fig. S17-S22). These data provide evidence that chemical reaction between biomass-bound olefins and sulfur is a requirement for homogenization. Further evidence that the strength of $\mathbf{P S}_{\boldsymbol{x}}$ is derived from the presence of the peanut oil is that a sample of pure sulfur is too brittle to survive clamping even at the minimum clamping force possible with the test instruments.
Many microscopically homogeneous HSMs are composites characterized by a sulfur-crosslinked organic network and some elemental sulfur that is not covalently linked to the organic component. Sulfur that is not covalently attached to the crosslinked network is readily extracted into $\mathrm{CS}_{2}$. Gravimetric and elemental analysis of the extractable sulfur and insoluble fractions were thus undertaken as a means to quantify the extent to which sulfur was covalently incorporated into the materials. Fractionation studies paired with evidence of quantitative consumption of olefins by infrared spectroscopy (Fig. S8 and S9, ESI $\$$ ) allow for the calculation of average number of sulfur atoms per crosslink, known as the sulfur rank. The results of these fractionation studies are summarized in Table 2. From these data, it can be observed that increasing the wt\% of organic in the material led to a decrease in $\mathrm{CS}_{2}$ solubility in all cases, as would be anticipated on the basis of available sites for covalent tethering of sulfur chains. The results observed for $\mathbf{A P S}_{\mathbf{9 5}}$ and $\mathbf{A P S} \mathbf{9 0}_{\mathbf{9 0}}$ were similar to what was observed with sulfur composites prepared from allyl cellulose alone, which had sulfur ranks of $\sim 20 .^{31}$ Surprisingly, composites $\mathbf{P S}_{\mathbf{9 0}}$ and $\mathbf{P S}_{\mathbf{9 5}}$ exhibited a lower fraction of $\mathbf{C S}_{2}$-extractable sulfur compared to their APS $_{\boldsymbol{x}}$ analogues. This observation could be due to longer polysulfur crosslinks or occurrence of crosslinking by reactions other than the typical inverse vulcanization. Based on the titratable alkenes in peanut shells, sulfur ranks were calculated to be as large as 330 and 257 for $\mathbf{P S}_{\mathbf{9 5}}$ and $\mathbf{P S}_{\mathbf{9 0}}$, respectively. Sulfur rank in $\mathbf{m A P S}_{\mathbf{9 5}}$ was somewhat larger than for corresponding $\mathbf{A P S}_{\boldsymbol{x}}$ but much smaller than $\mathbf{P S}_{\boldsymbol{x}}$ and was similar to that observed in composites made from allyl lignin and elemental sulfur. ${ }^{32}$

All of the materials had similar $T_{\mathrm{d}}$ values attributable to decomposition of $\mathbf{S}_{8}$ (Table 2). Both $\mathbf{A P S}_{\mathbf{9 5}}$ and $\mathbf{P S}_{\mathbf{9 5}}$ exhibited a second mass loss step at just above $300{ }^{\circ} \mathrm{C}$ that was not observed in the other materials (Fig. S10, ESI $\%$ ), likely a result of the more extensive crosslinking in these materials (vide infra). Char yields scaled predictably with the amount of organic content, with the exception of $\mathbf{P S}_{\mathbf{9 0}}$, which showed a larger than anticipated char yield, potentially due to attendant thermal crosslinking of hemicelluloses constituents that are not present in either the allylated peanut shells used to prepare $\mathbf{A P S}_{\boldsymbol{x}}$ or

Table 2 Morphological and thermal properties of biomass-sulfur composites

\begin{tabular}{|c|c|c|c|c|}
\hline Material & $\begin{array}{l}\mathrm{CS}_{2} \text { insoluble } \\
(\%)\end{array}$ & $\begin{array}{l}\text { Sulfur } \\
\operatorname{rank}^{b}\end{array}$ & $T_{\mathrm{d}}{ }^{c}\left({ }^{\circ} \mathrm{C}\right) \quad \begin{array}{l}T_{\mathrm{cc}}{ }^{d} \\
\left({ }^{\circ} \mathrm{C}\right)\end{array}$ & $\begin{array}{l}\text { Char yield }{ }^{e} \\
(\%)\end{array}$ \\
\hline $\mathbf{A P S}_{95}$ & 11 & 20 & $217 \pm 128-33$ & $1.7 \pm 0.4$ \\
\hline $\mathbf{A P S}_{90}$ & 23 & 21 & $215 \pm 225-28$ & $3.7 \pm 0.2$ \\
\hline $\mathbf{P S}_{95}$ & 14 & 330 & $223 \pm 422-24$ & $1.3 \pm 0.5$ \\
\hline $\mathbf{P S}_{90}$ & 24 & 257 & $217 \pm 133-34$ & $5.3 \pm 0.0$ \\
\hline mAPS $_{95}$ & 20 & 33 & $219 \pm 724-28$ & $2.1 \pm 0.0$ \\
\hline
\end{tabular}

${ }^{a}$ The percentage of material that was insoluble in $\mathrm{CS}_{2}$ after recursive washings. ${ }^{b}$ The average length of sulfur atoms per crosslink as determined by $\mathrm{CS}_{2}$ extraction. ${ }^{c}$ The temperature at which $5 \%$ of the material had decomposed by TGA. ${ }^{d}$ The range of cold crystallization temperatures observed in cycles 2-5 of DSC scans. ${ }^{e}$ The residual mass after heating to $800{ }^{\circ} \mathrm{C}$ at $10{ }^{\circ} \mathrm{C} \min ^{-1}$ under $\mathrm{N}_{2}$ as an average of duplicate runs with standard deviations. 
the constituents used to prepare $\mathbf{m A P S}_{\boldsymbol{x}}$. That lignin and hemicellulose improve one another's thermal stability in such a way has been established for synthetic hydrogels ${ }^{47}$ as well as for thermally-treated wood products. ${ }^{48-51}$

The differential scanning calorimetry (DSC) data revealed that all of the materials exhibited cold crystallization peaks but no observable $T_{\mathrm{g}}$ (full traces can be found in ESI, $\$$ Fig. S12-S16). The presence of cold crystallization peaks can be attributed to the confinement of $\mathrm{S}_{8}$ domains by crosslinked networks resulting in limited mobility and subsequent delayed recrystallization. Although this phenomenon has been reported for allyl lignin-sulfur composites containing $80-85 \mathrm{wt} \%$ sulfur, $^{32}$ the confinement in cellulose-sulfur networks was not sufficient to facilitate such cold crystallization. ${ }^{31}$

\section{Mechanical properties of biomass-sulfur composites}

The influence of monomer composition on the mechanical strength of HSMs has been surveyed in some detail by Chalker and Hasell. ${ }^{16}$ It has also recently been demonstrated that introduction of post-vulcanization urethane crosslinks vastly improves the mechanical properties of HSMs. ${ }^{52}$ With respect to lignocellulosic materials, we previously demonstrated methylpropenyl cellulose-sulfur composites having flexural strengths similar to those of familiar building materials like ordinary Portland cement (OPC), which has a flexural strength of 3-5 MPa, but those materials had apparently poor compressive strengths. Allyl lignin-sulfur composites exhibited poor flexural strength and the amount of allyl lignin that could be incorporated as a crosslinker was limited to under $5 \mathrm{wt} \%$ due at least in part to phase separation of lignin and sulfur phases and precipitation of allyl lignin when it was added in higher quantities. $^{32}$ Lignin-sulfur HSMs having improved monomer mixing at higher lignin loadings can be accomplished by RASP (radical aryl halide-sulfur polymerization) of chlorolignin and sulfur, leading to materials whose flexural strengths are also in the range of OPC. ${ }^{27}$ For the current context, each of the biomass crosslinking agents is comprised of both lignin and cellulose (Fig. 3).

The composites crosslinked by $5 \mathrm{wt} \%$ of biomass derivative exhibit similar flexural strengths, in the range of $130-150 \%$ that of OPC. The compressive strength, however, is significantly higher for $\mathbf{A P S}_{\mathbf{9 5}}$ than for the other biomass-sulfur composites and nearly twice that of OPC. Notably, the mAPS $_{\mathbf{9 5}}$ has only $49 \%$ the compressive strength of $\mathbf{A P S}_{\mathbf{9 5}}$ despite the fact that both of these composites were made using biomass crosslinkers consisting of the same cellulose-lignin ratio and olefin content in the material. While it is possible that the notably higher compressive strength of $\mathbf{A P S}_{\mathbf{9 5}}$ is attributable to cellulose-lignin crosslinking retained from those in the peanut shell precursor, it is also possible that the alkaline conditions to which the peanut shells were exposed for the allylation step catalysed some esterification of the carboxylate groups in lignin with cellulose-bound alcohol units. Phosphitylation of the lignin and quantification of carboxylate groups by ${ }^{31} \mathrm{P}$ NMR spectrometry with an internal standard ${ }^{53,54}$ confirmed that the lignin contains $0.36 \mathrm{mmol} \mathrm{\textrm {g } ^ { - 1 }}$ of carboxylate units that could

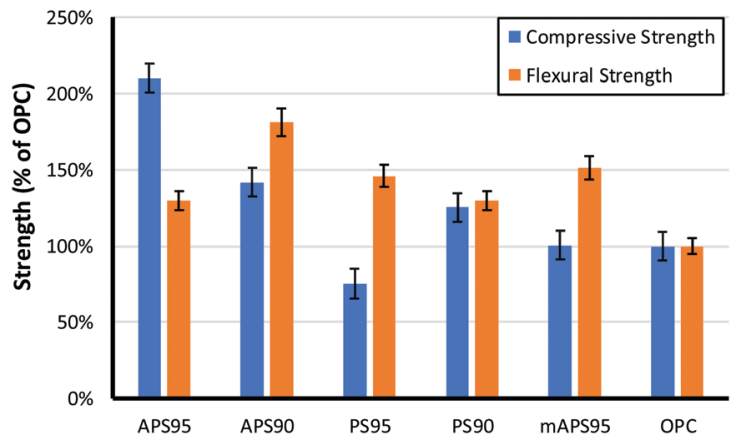

Fig. 3 Comparison of the compressive and flexural strength of biomasssulfur polymers to that of ordinary portland cement (OPC).

participate in esterification. There is also the possibility for thermal transesterification during heating, but this should also take place during formation of $\mathbf{~ M A P S}_{\mathbf{9 5}}$, so this possibility does not adequately explain the notable strength difference between the two composites.

As may be anticipated, the compressive strength of $\mathbf{P S}_{\mathbf{9 5}}$, in which crosslinking is provided only by peanut oil present in the peanut shells, had by far the lowest compressive strength, only $67 \%$ that of OPC and $36 \%$ that of $\mathbf{A P S}_{\mathbf{9 5}}$. If the amount of unmodified peanut shells (and thus crosslinkable olefins) is doubled, however, resulting composite $\mathbf{P S}_{\mathbf{9 0}}$ had flexural and compressive strengths exceeding those of Portland cement. The striking observation that unmodified peanut shells and sulfur can simply be heated together to produce a material that is stronger than cement was initially surprising. Such strength may initially seem higher than what might be expected on the basis of crosslinking by a small percentage of peanut oil in the absence of any covalent contribution by the lignin or cellulose. In contrast, the $\mathbf{d f P S}_{\boldsymbol{x}}$ samples proved to be primarily physical blends. Triglycerides, however, undergo transesterification in the absence of catalyst at temperatures above $170{ }^{\circ} \mathrm{C},{ }^{55}$ below the polymerization temperature used in the current study. ${ }^{56-59}$ Increased strength is thus expected to arise from ester functionalities in the peanut shell triglycerides undergoing facile transesterification with alcohol functionalities in lignin and cellulose during heating to $180{ }^{\circ} \mathrm{C}$. Such thermal transesterification would provide a mechanism for covalent bonding of the cellulose and lignin backbones to the network structure, accounting for the improved strength of the materials.

The compressive strengths of materials having $10 \mathrm{wt} \%$ biomass crosslinker are relatively similar to one another and are higher than those in OPC spanning 112-138\% that of OPC. Flexural strengths differed more significantly with $\mathbf{A P S}_{\mathbf{9 0}}$ having a flexural strength almost twice that of OPC while $\mathbf{P S}_{\mathbf{9 0}}$ exhibited a flexural strength only $30 \%$ larger. Perhaps most interestingly, increasing the ratio of organic for $\mathbf{A P S}_{\boldsymbol{x}}$ lead to improvements in flexural strengths while decreasing compressive strength whereas $\mathbf{P S}_{\boldsymbol{x}}$ showed the opposite trend. Although both PS and APS can act as crosslinkers and fillers, the ratio of these influences may be the culprit for the differences in mechanical properties with increasing organic content. Increases in crosslink density which occur more readily with APS provides significant improvements to 
Table 3 Mechanical properties of biomass-sulfur composites

\begin{tabular}{|c|c|c|c|c|}
\hline Material & $\begin{array}{l}\text { Compressive } \\
\text { strength }^{a} \\
\text { (MPa) }\end{array}$ & $\begin{array}{l}\text { Flexural } \\
\text { strength } \\
\text { (MPa) }\end{array}$ & $\begin{array}{l}\text { Flexural } \\
\text { modulus } \\
\text { (MPa) }\end{array}$ & $\begin{array}{l}\text { Modulus } \\
\text { of resilience } \\
\text { (Pa) }\end{array}$ \\
\hline $\mathbf{A P S}_{95}$ & $35.7 \pm 1.8$ & 4.8 & 690 & 180 \\
\hline $\mathbf{A P S}_{90}$ & $24.1 \pm 5.7$ & 6.7 & 1490 & 1180 \\
\hline $\mathbf{P S}_{95}$ & $12.8 \pm 0.0$ & 5.4 & 1360 & 860 \\
\hline $\mathbf{P S}_{90}$ & $21.3 \pm 1.2$ & 4.8 & 950 & 1020 \\
\hline mAPS $_{95}$ & $17.1 \pm 0.0$ & 5.6 & 1410 & 1550 \\
\hline $\mathbf{O P C}^{b^{93}}$ & $17^{c}$ & 3.7 & 580 & 560 \\
\hline $\begin{array}{l}\text { Polypropylene- } \\
\text { glass fibre } \\
\text { composite }^{d}\end{array}$ & - & 3.5 & 1350 & - \\
\hline ETFE $^{e}$ & 38 & - & 860 & - \\
\hline \multicolumn{5}{|c|}{$\begin{array}{l}{ }^{a} \text { All measured values based on the average of at least three trials. } \\
{ }^{b} \text { OPC is ordinary Portland cement. }{ }^{c} \text { Minimum value required for } \\
\text { residential building by building standard ACI } 332.1 \mathrm{R}-06 .{ }^{d} \text { Azdel Super- } \\
\text { Lite }^{\mathbb{R}} \text { SL550600-100. }{ }^{e} \text { Poly(ethylene-co-tetrafluoroethylene), Tefzel }{ }^{\mathrm{TM}}\end{array}$} \\
\hline
\end{tabular}

flexural properties while compressive properties can be improved by the addition of more filler (as was the case for $\mathbf{P S}_{\boldsymbol{x}}$ ). The limits of strength of both materials may also represent an upper limit to the influence of organic additive.

Given the generally quite low flexural strength but relatively high compressive strength of the biomass-sulfur composites, potential application spaces may be limited to static installations that do not require high flexibility. A few commercial products used in such applications include Portland cement, glass fibre-polypropylene composites (Azdel SuperLite ${ }^{\circledR}$ ) used in nonstructural automotive door panel components, ${ }^{60}$ and an ETFE product (Tefzel ${ }^{\mathrm{TM}}$ ETFE HT-2188, manufactured by Chemours) used commercially in electrical outlets/switches. ${ }^{61}$ The mechanical properties of these three commercial materials are provided in Table 3 . The compressive strength and flexural modulus of $\mathbf{A P S}_{\mathbf{9 5}}$ are quite comparable to those of the ETFE product, while composites having lower compressive strengths but higher flexural moduli $\mathbf{A P S}_{\mathbf{9 0}}, \mathbf{P S}_{\mathbf{9 5}}$ and $\mathbf{m A P S}_{\mathbf{9 5}}$ ) are more comparable to the glass fibre-polypropylene composites. The trade off of flexural and compressional metrics accessible to the biomass-sulfur composites based on the composition and biomass source thus hold potential to serve in variable application spaces.

\section{Conclusions}

In conclusion we report a facile strategy for the modification of waste biomass and its subsequent reaction with sulfur by inverse vulcanization to generate materials with mechanical properties significantly exceeding those of Portland cement. A remarkably simple route to robust, remeltable composites was revealed by heating native biomass waste with sulfur. In this case, control experiments suggest that the peanut oil triglycerides in the biomass are required for producing such composites. These strategies reported herein should be readily extendable to a near-unlimited array of waste biomass, yet the influence of even minute constituents such as plant oils must be considered in all cases to explain and predict the sources of material properties. Although no change in mechanical properties after the first seven days of curing was noted, the long-term curing behaviour will need to be characterized before commercialization of biomass-sulfur construction materials. Given that heating organics and sulfur to elevated temperatures can produce toxic $\mathrm{H}_{2} \mathrm{~S}$ gas, careful analysis of combustion products should also be undertaken for any organosulfur building material. In terms of developing mechanically durable materials the potential of biomass-sulfur composites as green surrogates seems to be limited predominantly by the immiscibility of biomass with sulfur, dictating further exploration of strategies to improve monomer compatibility. Increased organic incorporation, expansion of substrate scope, and increasingly green modification strategies may allow such biomass-sulfur materials to expand into commercial use.

\section{Experimental}

\section{General considerations}

Fourier transform infrared spectra were obtained using an IR instrument (Shimadzu IRAffinity-1S) with an ATR attachment. Scans were collected over the range $400-4000 \mathrm{~cm}^{-1}$ at ambient temperature with a resolution of 8 . TGA was recorded (Mettler Toledo TGA 2 STARe System) over the range $20-800{ }^{\circ} \mathrm{C}$ with a heating rate of $10{ }^{\circ} \mathrm{C} \mathrm{min}^{-1}$ under a flow of $\mathrm{N}_{2}\left(100 \mathrm{~mL} \mathrm{~min}{ }^{-1}\right)$. Each measurement was acquired in duplicate and presented results represent an average value. DSC was acquired (Mettler Toledo DSC 3 STARe System) over the range -60 to $150{ }^{\circ} \mathrm{C}$ with a heating rate of $5^{\circ} \mathrm{C} \mathrm{min}{ }^{-1}$ under a flow of $\mathrm{N}_{2}\left(200 \mathrm{~mL}^{-1} \mathrm{~min}^{-1}\right)$. Each DSC measurement was carried out over five heat-cool cycles. Each measurement was acquired in duplicate to ensure consistent results were obtained.

DMA was performed (Mettler Toledo DMA 1 STARe System) in single cantilever mode. DMA samples were cast from silicone resin moulds (Smooth-On Oomoo ${ }^{\circledR} 30$ tin-cure). Samples were manually sanded to ensure uniform dimensions. The sample dimensions were approximately $15 \times 8 \times 1.5 \mathrm{~mm}$ but due to instrumental limitations (maximum force of $10 \mathrm{~N}$ ), each sample differed slightly in thickness in order to obtain a stress at break. Sample dimensions were measured with a digital calliper with $\pm 0.01 \mathrm{~mm}$ resolution. The clamping force was $5 \mathrm{cN} \mathrm{m}$ for all materials. The force was varied from 0 to $10 \mathrm{~N}$ with a ramp rate of $0.2 \mathrm{~N} \mathrm{~min}^{-1}$ measured isothermally at $25{ }^{\circ} \mathrm{C}$.

Carbon disulfide extractions were performed by suspending $0.3 \mathrm{~g}$ of finely ground material (measured to $0.0001 \mathrm{~g}$ ) in $20 \mathrm{~mL}$ of $\mathrm{CS}_{2}$, allowing the solid to settle for 30 minutes, pipetting off the supernatant into a separate vial, and adding another $20 \mathrm{~mL}$ of $\mathrm{CS}_{2}$. This process was repeated an additional 3 times so that a total of 5 washes was performed. The residual $\mathrm{CS}_{2}$ was evaporated under a flow of $\mathrm{N}_{2}$ and each vial was weighed to determine the fraction that was soluble (collected as supernatant) or insoluble (remained in the initial vial).

SEM was acquired on a Schottky Field Emission Scanning Electron Microscope SU5000 operating in variable pressure mode with an accelerating voltage of $15 \mathrm{keV}$. Compressional analysis was performed on a Mark-10 ES30 test stand equipped 
with a M3-200 force gauge (1 $\mathrm{kN}$ maximum force with $\pm 1 \mathrm{~N}$ resolution). Compression cylinders were cast from silicone resin moulds (Smooth-On Oomoo ${ }^{\circledR} 30$ tin-cure) with diameters of approximately $6 \mathrm{~mm}$ and heights of approximately $10 \mathrm{~mm}$. Samples were manually sanded to ensure uniform dimensions and measured with a digital calliper with $\pm 0.01 \mathrm{~mm}$ resolution. Compressional analysis was performed in triplicate and results were averaged.

\section{Materials and methods}

Peanut shell powder (Golden Peanut and Tree Nuts, Product ES) elemental sulfur (99.5\%, Alfa Aesar), allyl bromide (99\% Alfa Aesar), sodium hydroxide ( $\geq 97 \%$ VWR Chemicals), acetic acid (glacial, XX) hexanes (certified ACS, Fisher), cellulose (Alfa Aesar), alkali lignin (Sigma Aldrich), allyl lignin (prepared and characterized in Karunarathna et al. ${ }^{32}$ ) were all used as received unless otherwise specified. Details on the synthesis and characterization of allyl cellulose and APS as well as the preparation of mAPS and dfPS can be found in the ESI + (pages 2-7, Fig. S2-S7, Table S1, ESI $\ddagger$ ).

\section{General composite synthesis}

A quantity of organic material (compensating for moisture as determined by duplicate TGA experiments) and sulfur totalling $10 \mathrm{~g}$ were weighed out and thoroughly mixed into a $20 \mathrm{~mL}$ scintillation vial equipped with a Teflon coated stir bar. The vials were sealed with polypropylene lids pierced with a needle to allow moisture to escape during reaction. The reactions were allowed to continue until visibly homogeneous (variable depending on the wt $\%$ and identity of the organic species). Samples were allowed to cure for at least 14 days before any further analysis. Specific material synthesis can be found in the ESI $¥$ (pages 8-9).

\section{Conflicts of interest}

There are no conflicts to declare.

\section{Acknowledgements}

We would like to thank Jake Harrell of Golden Peanut and Tree Nuts (Alpharetta, Georgia, USA) for supplying peanut shell product ES used in this study. Funding for this project from the National Science Foundation (CHE-1708844) is gratefully acknowledged. R. C. S. thanks John D. Protasiewicz of Case Western Reserve University for inspiring this work.

\section{Notes and references}

1 A. J. Ragauskas, G. T. Beckham, M. J. Biddy, R. Chandra, F. Chen, M. F. Davis, B. H. Davison, R. A. Dixon, P. Gilna, M. Keller, P. Langan, A. K. Naskar, J. N. Saddler, T. J. Tschaplinski, G. A. Tuskan and C. E. Wyman, Science, 2014, 344, 709.
2 S. N. Naik, V. V. Goud, P. K. Rout and A. K. Dalai, Renewable Sustainable Energy Rev., 2010, 14, 578-597.

3 Y. Sun and J. Cheng, Bioresour. Technol., 2002, 83, 1-11.

4 A. Gupta and J. P. Verma, Renewable Sustainable Energy Rev., 2015, 41, 550-567.

5 M. K. Lauer and R. C. Smith, Compr. Rev. Food Sci. Food Saf., 2020, 1-53, DOI: 10.1111/1541-4337.12627.

6 M. S. Karunarathna and R. C. Smith, Sustainability, 2020, 12, 734-748.

7 M. K. Lauer, M. S. Karunarathna, A. G. Tennyson and R. C. Smith, Mater. Adv., 2020, 1, 590-594.

8 T. Thiounn, M. S. Karunarathna, L. M. Slann, M. K. Lauer and R. C. Smith, J. Polym. Sci., 2020, 58, 1347-1364.

9 C. P. Maladeniya, M. S. Karunarathna, M. K. Lauer, C. V. Lopez, T. Thiounn and R. C. Smith, Mater. Adv., 2020, 1, 1665-1674.

10 C. V. Lopez, C. P. Maladeniya and R. C. Smith, Electrochem, 2020, 1, 226-259.

11 M. K. Lauer, A. G. Tennyson and R. C. Smith, ACS Appl. Polym. Mater., 2020, 2, 3761-3765.

12 S. Park, D. Lee, H. Cho, J. Lim and K. Char, ACS Macro Lett., 2019, 8, 1670-1675.

13 T. Hasell, P. Yan, W. Zhao, B. Zhang, S. Petcher, A. Smith Jessica, J. Parker Douglas, I. Cooper Andrew, L. Jiang and J. Lei, Angew. Chem., Int. Ed., 2020, 59, 2-10.

14 B. Zhang, H. Gao, P. Yan, S. Petcher and T. Hasell, Mater. Chem. Front., 2020, 4, 669-675.

15 B. Zhang, S. Petcher and T. Hasell, Chem. Commun., 2019, 55, 10681-10684.

16 J. A. Smith, S. J. Green, S. Petcher, D. J. Parker, B. Zhang, M. J. H. Worthington, X. Wu, C. A. Kelly, T. Baker, C. T. Gibson, J. A. Campbell, D. A. Lewis, M. J. Jenkins, H. Willcock, J. M. Chalker and T. Hasell, Chem. - Eur. J., 2019, 25, 10433-10440.

17 A. D. Tikoalu, N. A. Lundquist and J. M. Chalker, Adv. Sustainable Syst., 2020, 4, 1900111.

18 N. A. Lundquist, M. J. Sweetman, K. R. Scroggie, M. J. H. Worthington, L. J. Esdaile, S. F. K. Alboaiji, S. E. Plush, J. D. Hayball and J. M. Chalker, ACS Sustainable Chem. Eng., 2019, 7, 11044-11049.

19 M. J. H. Worthington, R. L. Kucera and J. M. Chalker, Green Chem., 2017, 19, 2748-2761.

20 M. J. H. Worthington, R. L. Kucera, I. S. Albuquerque, C. T. Gibson, A. Sibley, A. D. Slattery, J. A. Campbell, S. F. K. Alboaiji, K. A. Muller, J. Young, N. Adamson, J. R. Gascooke, D. Jampaiah, Y. M. Sabri, S. K. Bhargava, S. J. Ippolito, D. A. Lewis, J. S. Quinton, A. V. Ellis, A. Johs, G. J. L. Bernardes and J. M. Chalker, Chem. - Eur. J., 2017, 23, 16106.

21 M. P. Crockett, A. M. Evans, M. J. H. Worthington, I. S. Albuquerque, A. D. Slattery, C. T. Gibson, J. A. Campbell, D. A. Lewis, G. J. L. Bernardes and J. M. Chalker, Angew. Chem., Int. Ed., 2016, 55, 1714-1718.

22 C. Herrera, K. J. Ysinga and C. L. Jenkins, ACS Appl. Mater. Interfaces, 2019, 11, 35312-35318.

23 C. R. Westerman and C. L. Jenkins, Macromolecules, 2018, 51, 7233-7238. 
24 T. Thiounn and R. C. Smith, J. Polym. Sci., 2020, 58, 1347-1364.

25 A. D. Smith, R. C. Smith and A. G. Tennyson, Sustainable Chem. Pharm., 2020, 16, 100249.

26 A. D. Smith, C. D. McMillin, R. C. Smith and A. G. Tennyson, J. Polym. Sci., 2020, 58, 438-445.

27 M. S. Karunarathna, A. G. Tennyson and R. C. Smith, J. Mater. Chem. A, 2020, 8, 548-553.

28 M. S. Karunarathna, M. K. Lauer, A. G. Tennyson and R. C. Smith, Polym. Chem., 2020, 11, 1621-1628.

29 T. Thiounn, A. G. Tennyson and R. C. Smith, $R S C$ Adv., 2019, 9, 31460-31465.

30 A. D. Smith, T. Thiounn, E. W. Lyles, E. K. Kibler, R. C. Smith and A. G. Tennyson, J. Polym. Sci., Part A: Polym. Chem., 2019, 57, 1704-1710.

31 M. K. Lauer, T. A. Estrada-Mendoza, C. D. McMillen, G. Chumanov, A. G. Tennyson and R. C. Smith, Adv. Sustainable Syst., 2019, 3, 1900062.

32 M. S. Karunarathna, M. K. Lauer, T. Thiounn, R. C. Smith and A. G. Tennyson, J. Mater. Chem. A, 2019, 7, 15683-15690.

33 T. Thiounn, M. K. Lauer, M. S. Bedford, R. C. Smith and A. G. Tennyson, $R S C$ Adv, 2018, 8, 39074-39082.

34 A. Hoefling, Y. J. Lee and P. Theato, Macromol. Chem. Phys., 2017, 218, 1600303.

35 V. S. Wadi, K. K. Jena, K. Halique and S. M. Alhassan, ACS Appl. Polym. Mater., 2020, 2, 198-208.

36 V. S. Wadi, K. Halique and S. M. Alhassan, Ind. Eng. Chem. Res., 2020, 59, 13079-13087.

37 X. Wu, J. A. Smith, S. Petcher, B. Zhang, D. J. Parker, J. M. Griffin and T. Hasell, Nat. Commun., 2019, 10, 10035-10044.

38 S. J. Tonkin, C. T. Gibson, J. A. Campbell, D. A. Lewis, A. Karton, T. Hasell and J. M. Chalker, Chem. Sci., 2020, 11, 5537-5546.

39 N. A. Lundquist, A. D. Tikoalu, M. J. H. Worthington, R. Shapter, S. J. Tonkin, F. Stojcevski, M. Mann, C. T. Gibson, J. R. Gascooke, A. Karton, L. C. Henderson, L. J. Esdaile and J. M. Chalker, Chem. - Eur. J., 2020, 26, 10035-10044.

40 M. Mann, J. E. Kruger, F. Andari, J. McErlean, J. R. Gascooke, J. A. Smith, M. J. H. Worthington, C. C. C. McKinley, J. A. Campbell, D. A. Lewis, T. Hasell, M. V. Perkins and J. M. Chalker, Org. Biomol. Chem., 2019, 17, 1929-1936.
41 M. J. H. Worthington, C. J. Shearer, L. J. Esdaile, J. A. Campbell, C. T. Gibson, S. K. Legg, Y. Yin, N. A. Lundquist, J. R. Gascooke, I. S. Albuquerque, J. G. Shapter, G. G. Andersson, D. A. Lewis, G. J. L. Bernardes and J. M. Chalker, Adv. Sustainable Syst., 2018, 2, 1800024.

42 N. A. Lundquist, M. J. H. Worthington, N. Adamson, C. T. Gibson, M. R. Johnston, A. V. Ellis and J. M. Chalker, RSC Adv., 2018, 8, 1232-1236.

43 L. J. Esdaile and J. M. Chalker, Chem. - Eur. J., 2018, 24, 6905-6916.

44 C. V. Lopez, M. S. Karunarathna, M. K. Lauer, C. P. Maladeniya, T. Thiounn, E. D. Ackley and R. C. Smith, J. Polym. Sci., 2020, 58, 2259-2266.

45 P. Brown, I. Atly Jefcoat, D. Parrish, S. Gill and E. Graham, Adv. Environ. Res., 2000, 4, 19-29.

46 V. Dubois, S. Breton, M. Linder, J. Fanni and M. Parmentier, Eur. J. Lipid Sci. Technol., 2007, 109, 710-732.

47 B. Al-Rudainy, M. Galbe, O. Wallberg, M. Arcos Hernandez and P. Jannasch, Polymers, 2018, 11, 35.

48 R. Rowell, Cellul. Chem. Technol., 2012, 46, 443-448.

49 A. Ishikawa and T. Ohira, Mokuzai Kogyo, 2009, 64, 258-262.

50 J.-P. Haluk and M. Irmouli, J. Sci. Tech. Tonnellerie, 1998, 4, $1-82$.

51 P. Topf, Holz Roh- Werkst., 1971, 29, 269-275.

52 T. Hasell, P. Yan, W. Zhao, B. Zhang, S. Petcher, A. Smith Jessica, J. Parker Douglas, I. Cooper Andrew, L. Jiang and J. Lei, Angew. Chem., Int. Ed., 2020, 59, 2-10.

53 A. Granata and D. S. Argyropoulos, J. Agric. Food Chem., 1995, 43, 1538-1544.

54 D. S. Argyropoulos, J. Wood Chem. Technol., 1994, 14, 45-63.

55 M. Diasakou, A. Louloudi and N. Papayannakos, Fuel, 1998, 77, 1297-1302.

56 A. S. Reshad, P. Tiwari and V. V. Goud, Energy Fuels, 2017, 31, 9642-9651.

57 J.-J. Lin and Y.-W. Chen, J. Taiwan Inst. Chem. Eng., 2017, 75, 43-50.

58 J. Geuens, S. Sergeyev, B. U. W. Maes and S. M. F. Tavernier, Energy Fuels, 2013, 27, 2637-2642.

59 S. A. Pasias, N. K. Barakos and N. G. Papayannakos, Ind. Eng. Chem. Res., 2009, 48, 4266-4273.

60 Technical data sheet "Azdel SuperLite ${ }^{\circledR}$ SL550600-100" Supplied by Azdel April 30, 2020.

61 Technical data sheet "Tefzel ${ }^{\mathrm{TM}}$ ETFE HT-2188" Supplied by Chemours May 27, 2020. 